\title{
Radiation Effects in Nuclear Waste Materials
}

(Project Number: 73750)

\section{Principal Investigator}

William J. Weber

Pacific Northwest National Laboratory

P.O. Box 999, MSIN K8-93

Richland, WA 99352

(509) 376-3644

bill.weber@pnl.gov

\section{Co-Investigators}

Lumin Wang

Nuclear Engineering \& Radiological Sciences

The University of Michigan

2355 Bonisteel Boulevard

Ann Arbor, MI 48109-2104

(734) 647-8530

lmwang@umich.edu

Nancy J. Hess

Pacific Northwest National Laboratory

P.O. Box 999, MSIN P7-50

Richland, WA 99352

(509) 376-9808

nancy.hess@pnl.gov

B. Peter McGrail

Pacific Northwest National Laboratory

P.O. Box 999, MSIN K6-81

Richland, WA 99352

(509) 376-9193

pete.mcgrail@pnl.gov 


\section{Research Objective}

The objective of this project is to develop a fundamental understanding of radiation effects in glasses and ceramics, as well as the influence of solid-state radiation effects on aqueous dissolution kinetics. This study will provide the underpinning science to develop improved glass and ceramic waste forms for the immobilization and disposition of high-level tank waste, excess plutonium, plutonium residues and scrap, other actinides, and other nuclear waste streams. Furthermore, this study will develop predictive models for the performance of nuclear waste forms and stabilized nuclear materials. The research focuses on the effects of alpha and beta decay on defect production, defect interactions, diffusion, solid-state phase transformations, and dissolution kinetics. Plutonium incorporation, ion-beam irradiation, and electron-beam irradiation are used to simulate the effects of alpha decay and beta decay on relevant glasses and ceramics in experimental studies. Computer simulation methods are used to provide an atomic-level interpretation of experimental data and continuum-level modeling.

\section{Research Progress and Implications}

This report summarizes progress after 3 months of a 3-year project. While this is a renewal project, there has been a lapse of 18 months without funding. Since continuity of the research was disrupted, there has been no ongoing carryover research as normally would have been expected. Thus, most of the accomplishments in this short time to date have been in the recovery of radioactive samples from the previous project, reassembly of the research team, experimental design, and preparation of a large number of ceramic and glass samples for irradiation testing this year and next.

The co-investigator at the University of Michigan has yet to receive funding; however, a research plan has been developed, and samples are being prepared for shipment to the University of Michigan as soon as they receive funding to begin their research task.

\section{Planned Activities}

\section{Alpha-Decay Effects in Glasses and Ceramics}

It is critical to determine the local changes in structure of the boron in the three Pu-doped glasses that have been studied previously under this project, as this may be important to understanding the changes in dissolution kinetics. These measurements will be carried out using the Advanced Light Source. The presence of any molecular oxygen that may have been produced in these glasses because of radiation-induced decomposition will be probed using Raman and infrared photoluminescence.

Since some dissolution measurements were performed on the Pu-doped glasses immediately after preparation in 1982, the same dissolution measurements will be performed on these glasses in their current radiation-damaged state for comparison. In addition, we will perform a comprehensive set of dissolution kinetics experiments with the ${ }^{239} \mathrm{Pu}$-doped glass (lightly 
damaged) and the ${ }^{238} \mathrm{Pu}$-doped glass (highly damaged) using the single-pass flow-through (SPFT) test method to measure the forward reaction rate of these glasses as a function of temperature and $\mathrm{pH}$.

An annealing study of the amorphous ${ }^{238} \mathrm{Pu}$-zircon will be carried out at 600,700 , and $800^{\circ} \mathrm{C}$, and we will perform XAS measurements, as before, to understand the early stages of annealing. This recovery process is critically important to developing and validating long-term predictive models. In addition, we will use Raman spectroscopy to measure the decrease in width of the antisymmetric stretching vibrational band of the $\mathrm{SiO}_{4}$ tetrahedra in the $\mathrm{Pu}$-zircons as a function of annealing temperature.

\section{Electron and Ion Irradiation Studies}

The University of Michigan will lead studies on using electron beams and light-ion $\left(\mathrm{H}^{+}, \mathrm{He}^{+}\right)$ beams to study the effects of ionization (from beta and alpha decay) on the structure and stability of glasses. Heavy-ion irradiation will also be used to simulate the radiation effects induced by alpha-recoil particles. During the ion-beam irradiation, an in situ transmission electron microscopy study will be performed using the IVEM-Tandem facility at Argonne National Laboratory.

Ion-irradiation experiments conducted at Pacific Northwest National Laboratory will employ a range of ions in continued studies of irradiation effects in ceramics that may be relevant to the Nuclear Materials Focus Area and for special waste streams (e.g., Cs immobilization). Phases of interest include apatite, zircon, silicotitanate, rare-earth titanates, and rare-earth zirconates. Irradiations will be performed on high-density sintered samples. We will perform small-angle $\mathrm{X}$-ray diffraction and dissolution measurements on bulk samples.

\section{Information Access}

Weber WJ. 2000. Radiation Effects in Nuclear Waste Materials, Final Report, EMSP Project Number 54672 (http://emsp.em.doe.gov/products.htm).

Begg BD, NJ Hess, WJ Weber, R Devanathan, JP Icenhower, S Thevuthasan, and BP McGrail. 2001. "Heavy-Ion Irradiation Effects on Structures and Acid Dissolution of Pyrochlores," Journal of Nuclear Materials 288[2-3]:208-216. 